\title{
Suicide gene-modified killer cells as an allogeneic alternative to autologous cytokine-induced killer cell immunotherapy of hepatocellular carcinoma
}

\author{
TAO WU ${ }^{1-3}$, CÉLINE LEBOEUF ${ }^{2,3}$, SARAH DURAND $^{2,3}$, BIN SU $^{2,3}$, MARINA DESCHAMPS $^{4-6}$, \\ XIAOWEN ZHANG ${ }^{1}$, CHRISTOPHE FERRAND ${ }^{4-6}$, PATRICK PESSAUX ${ }^{2,3,7,8}$ and ERIC ROBINET ${ }^{2,3,8}$
}

\footnotetext{
${ }^{1}$ Department of Hepatobiliary and Pancreatic Surgery, Second Affiliated Hospital of Kunming Medical University, Kunming, Yunnan 650500, P.R. China; ${ }^{2}$ French National Institute of Health and Medical Research and ${ }^{3}$ University of Strasbourg, Research Unit 1110, F-67000 Strasbourg; ${ }^{4}$ French National Blood Service (Bourgogne/Franche-Comté) and

${ }^{5}$ French National Institute of Health and Medical Research; ${ }^{6}$ University of Franche-Comté, Research Unit 1098, F-25000 Besançon; ${ }^{7}$ Hepatodigestive Pole, New Civil Hospital, University Hospital of Strasbourg;

${ }^{8}$ Institute of Image-Guided Surgery, University Hospital Institute of Strasbourg, F-67000 Strasbourg, France
}

Received April 21, 2015; Accepted December 15, 2015

DOI: $10.3892 / \mathrm{mmr} .2016 .4811$

\begin{abstract}
Adoptive immunotherapy using autologous cytokine-induced killer (CIK) cells reduces the recurrence rate of hepatocellular carcinoma (HCC) in association with transarterial chemoembolization or radiofrequency. However, a large-scale development of this immunotherapy remains difficult to consider in an autologous setting, considering the logistical hurdles associated with the production of this cell therapy product. A previous study has provided the in vitro and in vivo proof-of-concept that allogeneic suicide gene-modified killer cells (aSGMKCs) from healthy blood donors (a cell therapy product previously demonstrated to provide anti-leukemic effects to patients receiving allogeneic hematopoietic transplantation) may exert a potent anti-tumor effect towards HCC. Therefore, the development of a bank of 'ready-for-use' aSGMKCs was proposed as an approach allowing for the development of immunotherapies that are more convenient and on a broader scale than that of autologous therapies. In the present study, aSGMKCs were compared with CIK cells generated according to three different protocols. Similar to CIK cells, the cytotoxic activity of aSGMKCs toward the Huh-7 HCC cell line was mediated by tumor necrosis factor-related apoptosis-inducing ligand, tumor necrosis factor- $\alpha$ and interferon- $\gamma$. Furthermore, the frequency of natural killer (NK), NK-like T and T cells, and
\end{abstract}

Correspondence to: Dr Eric Robinet, Institute of Image-Guided Surgery, University Hospital Institute of Strasbourg, 1 Place de l'Hôpital, F-67000 Strasbourg, France

E-mail: eric.robinet@ihu-strasbourg.eu

Key words: adoptive immunotherapy, hepatocellular carcinoma, suicide gene-modified lymphocyte, cytokine-induced killer cell, cell therapy, gene therapy, alloreactivity their in vitro and in vivo cytotoxicity activities were similar between aSGMKCs and CIK cells. Thus, the present study demonstrated that aSGMKCs are similar to CIK cells, further suggesting the possibility for future use of aSGMKCs in the treatment of solid tumors, including HCC.

\section{Introduction}

Hepatocellular carcinoma (HCC) is the second most common cause of cancer-associated mortality worldwide and the leading cause of mortality among cirrhotic patients (1). Early-stage tumors may be curatively treated using surgical approaches; however, they are often undiagnosed and treatment options for advanced $\mathrm{HCC}$, including transarterial chemoembolization (TACE) and radiofrequency ablation (RFA), are unsatisfactory. The multikinase inhibitor sorafenib has been identified to improve the survival benefit for patients with locally advanced or metastatic HCC; however, adverse side effects and moderate efficacy limit its use in patients with advanced liver disease (2). Therefore, it is important to develop a therapy for advanced HCC that is well-tolerated, cost-effective and poses an acceptable risk-to-benefit ratio.

Cytokine-induced killer (CIK) cells, generated by ex vivo expansion of peripheral blood mononuclear cells (PBMCs), have been described as exerting a highly potent, non-major histocompatibility complex (MHC)-restricted, $\mathrm{CD}^{+} / \mathrm{CD}^{2} 6^{+}$, natural killer-like $\mathrm{T}$ cell-mediated cytotoxic activity in solid tumors (3-6), while exhibiting a low capacity to induce graft-versus-host disease (GvHD) $(7,8)$. Autologous immunotherapy with CIK cells has been evaluated toward different solid tumors, including HCC $(9,10)$, and was demonstrated, in association with TACE and RFA or as adjuvant therapy, to increase median time to progression, progression-free survival and overall survival for post-operative patients (11-14). Randomized studies comparing TACE, RFA and/or surgery with or without autologous immunotherapy using patient-derived CIK cells indicated that immunotherapy 
significantly reduces the recurrence rate of $\mathrm{HCC}$ and increases the overall and progression-free survival of patients with HCC (15-18). A previous study performed a meta-analysis and confirmed the benefits of combining CIK immunotherapy with conventional treatments (19). However, a large-scale development of this immunotherapy remains difficult to consider in an autologous setting, due to the logistical hurdles associated with the production of this cell therapy product (CTP). A previous study provided the in vitro and in vivo proof-of-concept that another CTP, termed allogenic suicide gene-modified killer cells (aSGMKCs), may provide a potent anti-tumor effect toward HCC (20). This CTP has been previously demonstrated to provide an anti-leukemic effect when infused to patients receiving bone marrow transplantation (21), with no major acute toxicity upon infusion. Long-term monitoring of patients demonstrated the safety of this approach $(22,23)$. In the event of severe side effects, including the induction of GvHD, the prior retroviral vector-mediated transfer of a suicide gene in these cells allows them to be efficiently killed by infusion of a prodrug, leading to an efficient control of possible side effects (24-27). Therefore, the production of a bank of 'ready-for-use' aSGMKCs from healthy blood donors was proposed as an innovative approach, to allow for the development of immunotherapies on a more convenient and broader scale than for that of autologous therapies. This approach is more attractive, due to several reasons. Firstly, CTP production is easier to perform when using lymphocytes from normal donors, as they typically expand more efficiently than those from heavily-treated patients $(28,29)$. Additionally, a 'ready-for-use' allogeneic CTP may be rapidly infused into the patient, without the time required for the production and qualification of a patient-specific CTP (an autologous or patient-directed CTP) (30). Furthermore, there is no risk of losing a clinical-grade CTP batch; if a cell batch planned to be infused to a given patient is not administered due to medical contra-indication or non-compliance, it may still be used later for another patient (30). Although the gene transfer adds technical complexity during the production of aSGMKCs, as compared with the process of CIK cell production, previous studies have indicated the feasibility of producing large quantities of clinical-grade aSGMKCs (31-33).

Considering their functional similarities [including potent and non-MHC class I-restricted, NK and NK-like T-cell-mediated cytotoxic activity and a low potential of GvHD induction $(20,34,35)]$, the present study aimed to compare aSGMKCs and CIK cells.

\section{Materials and methods}

Production of effector cells. Allogeneic SGMKCs were produced as previously described (34). Buffy coats of 35 healthy anonymous volunteer blood donors (purchased from the French National Blood Service following receipt of their written informed consent for research use of their blood donation) were used as a source of PBMCs. Buffy coats were obtained by centrifugation over a Ficoll layer (Invitrogen; Thermo Fisher Scientific, Inc., Waltham, MA, USA) at $360 \mathrm{x} \mathrm{g}$ for $20 \mathrm{~min}$ at $20^{\circ} \mathrm{C}$. PMBCs were activated with $10 \mathrm{ng} / \mathrm{ml}$ CD3 monoclonal antibody (mAb) Orthoclone OKT3 (OKT3; Janssen-Cilag, Levallois-Perret, France) and 500 IU/ml human interleukin-2 (IL-2; Proleukin; Novartis Pharmaceuticals Canada, Inc., Dorval, QC, Canada), and transduced on day 3 with the MP71-T34FT retroviral vector (Eufets $\mathrm{GmbH}$, Idar-Oberstein, Germany) encoding the truncated form of the human CD34 (selection marker) fused to the Herpes simplex virus thymidine kinase (HSV-tk) suicide gene (36) or the SFG.iCasp9.2A.ACD19 retroviral vector (provided by Professor M.K. Brenner, Center for Cell and Gene Therapy, Baylor College of Medicine, Houston, TX, USA) encoding the human CD19 (selection marker) and the inducible caspase-9 (iCasp9) suicide gene (26). Cells were then immunomagnetically selected on day 5 with an autoMACS Pro Separator (Miltenyi Biotec SAS, Paris, France), based on the expression of the CD34 or CD19 membrane markers, and expanded until day 14. Transduced and CD34 or CD19-selected cells were referred to as aSGMKCs, while non-transduced cells that expanded in parallel for 14 days were termed control cells. The transduction efficiency (percentage of CD34 or CD19-positive cells following transduction) was $8.6 \pm 1.0 \%(n=13)$ and $51.2 \pm 6.1 \%(n=3)$, and the purity of the immunomagnetically selected fraction was $92.4 \pm 1.1 \%(n=13)$ and $94.8 \pm 0.4 \%(n=3)$ for CD34/HSV-tk and CD19/iCasp9-transduced cells, respectively. Relative cell growth was calculated as the ratio of the number of cells (counted using a B-500 microscope; Optika, Ponteranica, Italy) of the indicated phenotype obtained at the end of the expansion at $37^{\circ} \mathrm{C}$ (day 14) to the input number of cells of the specific phenotype at initiation of the culture (day 0).

CIK cell production. The cells were produced according to three previously published protocols: Protocol 1 (P1), PBMC activation with $100 \mathrm{U} / \mathrm{ml}$ interferon- $\gamma$ (IFN- $\gamma$; PeproTech, Inc., Neuilly-sur-Seine, France) at day 0 and $10 \mathrm{ng} / \mathrm{ml}$ OKT3 + $500 \mathrm{U} / \mathrm{ml} \mathrm{IL-2} \mathrm{at} \mathrm{day} 1(9,37)$. These cells were referred to as CIK P1. Protocol 2 (P2), PBMC activation with $100 \mathrm{U} / \mathrm{ml} \mathrm{IFN}-\gamma$ at day 0 and $10 \mathrm{ng} / \mathrm{ml} \mathrm{OKT} 3+500 \mathrm{U} / \mathrm{ml}$ IL-2 + $100 \mathrm{U} / \mathrm{ml} \mathrm{IL-1} \mathrm{(PeproTech,} \mathrm{Inc.)} \mathrm{at} \mathrm{D0} \mathrm{(11,15).} \mathrm{These}$ cells were referred to as CIK P2. Protocol 3 (P3): PBMCs activation with $10 \mathrm{ng} / \mathrm{ml} \mathrm{OKT3} \mathrm{+} 500 \mathrm{U} / \mathrm{ml} \mathrm{IL-2} \mathrm{+} 20 \mathrm{ng} / \mathrm{ml}$ IL-7 (PeproTech, Inc.) + $20 \mathrm{ng} / \mathrm{ml} \mathrm{IL-15} \mathrm{(PeproTech,} \mathrm{Inc.)} \mathrm{at}$ day 0 (38). These cells were referred to as CIK P3. All cells were expanded until day 14 in culture medium consisting in RPMI 1640 medium (Invitrogen; Thermo Fisher Scientific, Inc.) supplemented with $10 \% \mathrm{v} / \mathrm{v}$ human serum and $500 \mathrm{U} / \mathrm{ml}$ IL-2.

Flow cytometry. Effector cells were analyzed for the relative repartition of $\mathrm{CD}^{-} / \mathrm{CD}^{2} 6^{+} \mathrm{NK}, \mathrm{CD}^{+} / \mathrm{CD}^{2} 6^{+} \mathrm{NK}-$ like $\mathrm{T}$ and $\mathrm{CD}^{+} / \mathrm{CD}^{-} 6^{-} \mathrm{T}$ cells following staining with Pacific Blue-conjugated CD3 mAb (BD Biosciences, San Diego, $\mathrm{CA}, \mathrm{USA}$ ) and phycoerythrin-cyanin (PE-Cy)5-conjugated CD56 mAb (Miltenyi Biotec GmbH, Bergisch Gladbach, Germany). The purity of aSGMKCs was evaluated by flow cytometry following staining with $\mathrm{PE}-\mathrm{Cy} 7$-conjugated $\mathrm{mAb}$ specific for CD34 or CD19 (BD Biosciences). Multi-color samples were acquired on a LSRII special order research product flow cytometer (LSRII; BD Biosciences) calibrated using a Cytometer Setup \& Tracking Beads kit (BD Biosciences) to ensure consistency of fluorescence intensity measurement throughout all experiments. Compensation was 
performed with a CompBeads kit (cat. no. 51-90-9001229; BD Biosciences). Cell debris and dead cells were excluded using forward scatter area and side scatter area and doublet cells were excluded using side scatter width and side scatter area. FACSDiva software (version 6.1.2; BD Biosciences) was used for the final analysis and graphical output.

In vitro cytotoxicity assay. Target cells (1,500 HeLa, Huh-7 cells/we11, 2,500 SK-Hep1 cells/well, 20,000 PLC-PRF/5 cells/well; American Type Culture Collection, Molsheim, France) were co-cultured in RPMI 1640 medium (with $500 \mathrm{U} / \mathrm{ml}$ IL-2) in the presence or absence of graded quantities of effector cells for 6 days in flat bottom 96-well plates and, when indicated, in the presence of monoclonal mouse anti-human tumor necrosis factor- $\alpha$ (TNF- $\alpha$; clone MAb1; cat. no. 16-7348), monoclonal mouse anti-human IFN- $\gamma$ (clone NIB42; cat. no. 16-7318), monoclonal mouse anti-human Fas-ligand (Fas-L; clone NOK-1; cat. no. 16-9919) or monoclonal mouse anti-human TNF-related apoptosis inducing ligand (TRAIL; clone RIK-2; cat. no. 16-9927) mAbs (5 $\mu \mathrm{g} / \mathrm{ml}$; eBiosciences, Inc., San Diego, CA, USA; 1:100). Subsequently, non-adherent effector cells and dead target cells were removed by washing with phosphate-buffered saline (PBS), and the remaining viable, adherent target cells were stained with crystal violet (Sigma-Aldrich, St. Louis, MO, USA) at room temperature for $1 \mathrm{~min}$. Absorbance was read at $560 \mathrm{~nm}$ on a Mithras LB940 microplate reader (Berthold Technologies GmbH \& Co., Thoiry, France). Data are expressed as percentage killing, at the indicated effector:target (E:T) cell ratios as: $\left[1\right.$ - $\left(\right.$ Abs. $_{\text {E:T }} /$ Abs. $\left.\left._{\text {Ctrle }}\right)\right]$ x 100, where Abs.E:T indicates the absorbance at a given E:T ratio and Abs.Ctrle is the absorbance of target cells alone $(\mathrm{E}: \mathrm{T}=0)$. Percentage killing is then expressed as lytic units 50\% (LU50), calculated as the reverse of the number of cells per $10^{6}$ effector cells required to kill $50 \%$ of target cells (Fig. 1). LU50 of the experimental groups were normalized to the LU50 values of their control group, in order to normalize inter-experimental variations, and expressed as the mean \pm standard error (20).

CD107a degranulation assay. Lymphokine-activated killer (LAK) cells were generated by activating PBMCs with IL-2 $(1,000 \mathrm{U} / \mathrm{ml})$ for 4 days. The effector cells (aSGMKCs or LAK cells) and target cells (Huh-7 cells or K562 cells, used as positive control of lysis) were co-incubated at $37^{\circ} \mathrm{C}$ in culture medium at an E:T cell ratio of 4:1 in the presence of monoclonal mouse anti-human PE-CD107a (cat. no. 555801) or isotype control antibody (10 $\mu 1$ per $10^{6}$ effector cells; BD Biosciences; 1:10) to a total volume of $100 \mu \mathrm{l}$ in a flat bottom 96-well plate. After $1 \mathrm{~h}, 50 \mu \mathrm{l}$ culture medium containing brefeldin A (10 $\mu \mathrm{g} / \mathrm{ml})$ and GolgiStop ( $4 \mu \mathrm{l}$ for $6 \times 10^{6}$ cells; BD Biosciences) were added for a further $3 \mathrm{~h}$ incubation. The effector cells were then labeled in cytometry tubes with Pacific Blue-conjugated $\mathrm{CD} 3 \mathrm{mAb}$ and PE-Cy5-conjugated CD56 mAb, washed twice with $3 \mathrm{ml}$ PBS (Invitrogen; Thermo Fisher Scientific, Inc.), fixed with PBS supplemented with $2 \% \mathrm{v} / \mathrm{v}$ formaldehyde (Merck Millipore, Darmstadt, Germany), and analyzed by flow cytometry (LSRII).

Ethical approval. Animal experimentations were performed following approval by the local ethical committee (Comité

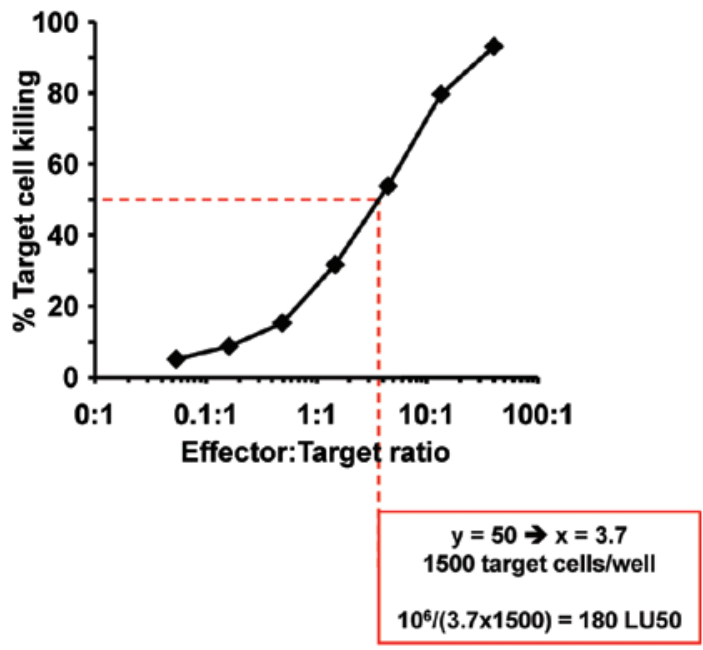

Figure 1. Determination of LU50. The percentage of target cell killing by aSGMKCs (in this example, 1,500 Huh-7 target cells/well) was plotted against the effector cell to produce the target cell ratio. LU50 was calculated as the reverse of the number of cells/106 effector cells required to kill $50 \%$ of the target cells. In this representative experiment, the cytotoxic activity was calculated to be 180 LU50. LU50, lytic units 50\%; aSGMKCs, allogeneic suicide gene-modified killer cells.

Régional d'Ethique en Matière d'Expérimentation Animale de Strasbourg; approval no. AL/34/41/02/13) on November 7, 2012, according to European guidelines (directive 2010/63/UE) and relevant national rules. For ethical reasons, mice were not monitored until tumor-associated mortality but were sacrificed at the end of experiments by cervical dislocation following general anesthesia with $3 \%$ isoflurane.

In vivo cytotoxicity assays. In vivo cytotoxicity assays were performed as previously described (20). Luciferase-expressing Huh-7 target cells (1x10 ${ }^{6}$ Huh-7-Luc cells) were subcutaneously co-injected into the right flank of 86 severe combined immunodeficient-beige (SCIB-bg) recipient mice (Taconic Biosciences, Inc., Ejby, Denmark) in the absence (PBS, $\mathrm{n}=13$ ) or presence of $10 \times 10^{6}$ iCasp9-expressing aSGMKCs effector cells (CIK P1, n=14; CIK P2, n=17; CIK P3, n=13; iCasp9-expressing aSGMKCs, $\mathrm{n}=17$ ). Daily intraperitoneal injections of IL-2 $\left(10^{6} \mathrm{IU} / \mathrm{kg}\right)$ were administered throughout the duration of the experiment. When indicated, an intraperitoneal injection of the iCasp9 prodrug [AP20187; also termed chemical inducer of death (CID); Clontech Laboratories, Saint Germain en Laye, France] at $2.5 \mathrm{mg} / \mathrm{kg}$ was performed together with the aSGMKCs injection $(n=12)$. Eight-to-twelve week-old male and female mice were used and randomly distributed in experimental groups. The mice were housed under specific pathogen-free conditions with food and drinking water containing $1 \mathrm{mg} / \mathrm{ml}$ paracetamol (Doliprane 300; Sanofi-Aventis, Paris, France) ad libitum. Luciferase activity of Huh-7-Luc cells, determined by bioluminescence imaging (BLI) using an IVIS Lumina Series II camera (PerkinElmer, Roissy, France) following an intraperitoneal injection of $100 \mu \mathrm{l}$ luciferin (20 mg/ml; Caliper Lifesciences), was determined at the time of target cell injection on days $0,4,7,11$ and 14. Tumor cell bioluminescence, analyzed with Living Image software (version 3.1; PerkinElmer), was quantified in a round-shape 
A

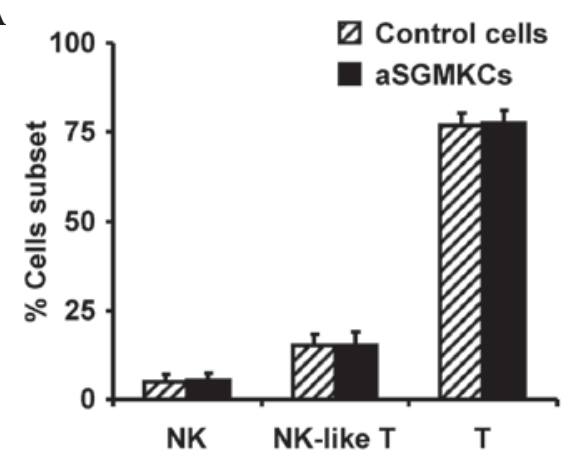

B

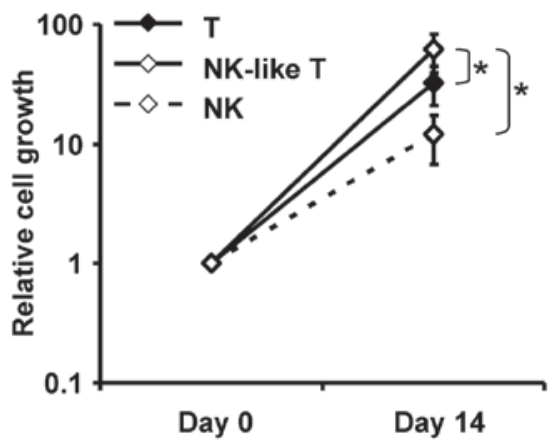

Figure 2. Phenotypic profile of aSGMKCs. (A) The frequency of CD3- CD56 ${ }^{+} \mathrm{NK}, \mathrm{CD}^{+} \mathrm{CD}^{-} 6^{+} \mathrm{NK}^{-1 i k e} \mathrm{~T}$ cells and CD3 ${ }^{+} \mathrm{CD} 56^{-} \mathrm{T}$ cells in aSGMKCs is similar to that of control cells activated and expanded in parallel with aSGMKCs, but not transduced. Data are expressed as the mean \pm standard error of 13 independent donors. (B) Within aSGMKCs, the relative cell growth (the ratio of cells obtained at day 14 to the input cell number at day 0 ) of NK-like $\mathrm{T}$ cells is significantly higher $\left({ }^{*} \mathrm{P}<0.05\right)$ to that of $\mathrm{NK}$ or $\mathrm{T}$ cells. Data are expressed as the mean \pm standard error of 13 independent donors. aSGMKCs, allogeneic suicide gene-modified killer cells, NK, natural killer.

region of interest centered on the cell injection site and was expressed as photons $/ \mathrm{sec} / \mathrm{cm}^{2} /$ steradian $\left(\mathrm{p} / \mathrm{sec} / \mathrm{cm}^{2} / \mathrm{sr}\right)$. Relative tumor growth was obtained by calculating the ratio of bioluminescence at the indicated day to the bioluminescence at day 0 . A relative tumor growth value of $\leq 1$ indicated tumor cell elimination and a value of $>1$ indicated an expansion of tumor cells.

Statistical analysis. Data that was not normally distributed was compared with Mann-Whitney U or Fisher's exact non-parametric tests; when data distribution was normal, Student's paired t-test was used. Data are expressed as the mean \pm standard error. A $\chi^{2}$ test was performed to compare the number of animals with and without relapse in the experimental groups compared with the control group. $\mathrm{P}<0.05$ indicates a statistically significant difference.

\section{Results}

Phenotypic characterization of aSGMKCs. As previously reported $(20,35)$, aSGMKCs were predominantly constituted of $\mathrm{CD}^{+} / \mathrm{CD}^{-} 6^{-} \mathrm{T}$ cells, then by $\mathrm{CD}^{+} / \mathrm{CD}^{2} 6^{+} \mathrm{NK}$-like $\mathrm{T}$ cells and to a lesser extent by $\mathrm{CD} 3{ }^{-} / \mathrm{CD}^{2} 6^{+} \mathrm{NK}$ cells. Other mononuclear subsets, including B cells or monocytes, were not detectable (Fig. 2A). This repartition was similar to the one observed in non-transduced control cells that were activated and expanded in parallel with aSGMKCs (Fig. 2A). This indicates that the cell culture process was responsible for these phenotypical modifications and that the gene transfer process did not lead to the preferential transduction or selection of a lymphocyte population. Furthermore, the ex vivo expansion was associated with a significantly higher relative expansion of NK-like T cells than that observed with NK or T cells $(\mathrm{P}<0.05$; Student's paired t-test; Fig. 2B).

Mechanism of aSGMKC-mediated killing of hepatoma cells. As previously reported, aSGMKCs may provide a potent cytotoxic activity toward various liver-derived cell lines, such as Huh-7, PLC-PRF5 (HCC cell lines) and SK-Hep1, and toward the cervical carcinoma cell line HeLa (20). The cytotoxic activity of aSGMKCs, evaluated at different E:T ratios, indicated that 50 and $90 \%$ target cell killing were obtained at mean E:T ratios of $\sim 3: 1$ and $\sim 13: 1$ to 40:1, respectively (Fig. 3A), excluding PLC-PRF5 cells, which were more sensitive to aSGMKC-mediated killing. It was previously reported that the cytotoxic activity of aSGMKCs, evaluated in more detail toward Huh-7 cells, was HLA class-I independent and was predominantly mediated by $\mathrm{CD}^{2} 6^{+} / \mathrm{CD}^{-} \mathrm{NK}$ and $\mathrm{CD}^{2} 6^{+} / \mathrm{CD}^{+} \mathrm{NK}$-like $\mathrm{T}$ cells (20). In order to further characterize the mechanisms of target cell killing, the involvement of the granzyme/perforin pathway was evaluated by CD107a staining of aSGMKCs (and of LAK cells, used as a positive control of non-MHC-restricted cytotoxic cells) following incubation with Huh-7 cells (or K562 cells, used as a control of LAK-sensitive target cells). Following co-incubation with Huh-7 cells, the frequency of CD107a-positive cells, corresponding to effector cells with degranulated lytic granules, were higher in LAK cells than in aSGMKCs generated from the specific donors (Fig. 3B). A similar trend was observed, to a greater extent, when effector cells were incubated with K562 cells (Fig. 3B). Regardless of the E:T cell combinations, the frequency of CD107a-positive cells was higher in the NK cell subset than in the NK-like T cell subset, while no induction of CD107a expression was observed in $\mathrm{T}$ cells (Fig. 3C). Overall, considering that the frequency of NK and NK-like T cells was lower than that of T cells (Fig. 2A), the induction of CD107a expression in aSGMKCs following incubation with Huh-7 cells was minimal, suggesting that other killing mechanisms may be involved.

Thus, in vitro cytotoxicity assays were performed in the presence or absence of antibodies targeting IFN- $\gamma$, TNF- $\alpha$, Fas-L or TRAIL. The cytotoxic activity of aSGMKCs was not affected by the addition of anti-IFN- $\gamma$ or anti-TNF- $\alpha$ antibodies alone but a significant $(\mathrm{P}<0.05$; Mann-Whitney $\mathrm{U}$ test; Fig. 3D) reduction of the cytotoxicity level was observed when both antibodies were added, suggesting a synergistic involvement of IFN- $\gamma$ and TNF- $\alpha$ in target cell killing. TRAIL-mediated killing was also involved in aSGMKC-induced killing, as demonstrated by the significant $(\mathrm{P}<0.05$; Mann-Whitney $\mathrm{U}$ test; Fig. 3D) inhibitory effect of blocking anti-TRAIL antibodies on the cytotoxicity level. Blocking anti-Fas-L antibodies had no significant inhibitory effect on sSGMKCs cytotoxicity but enhanced the reduction of cytotoxicity by anti-TRAIL antibodies $(\mathrm{P}<0.05$; Fig. 3D). 
A

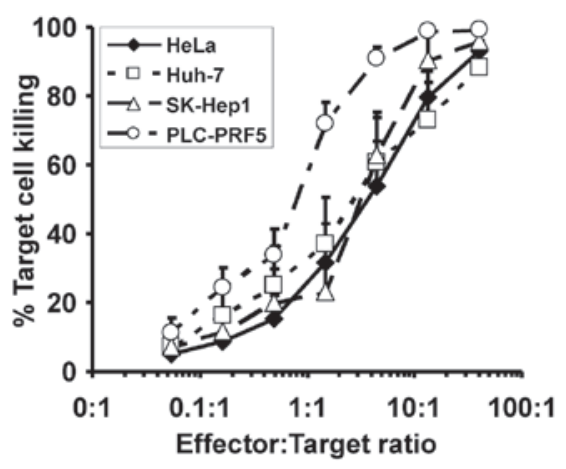

C

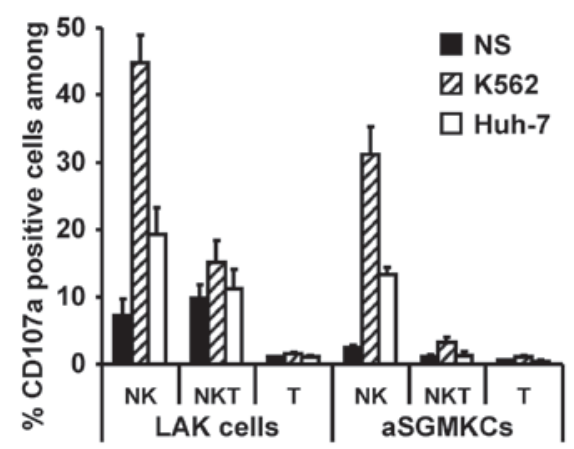

B



D

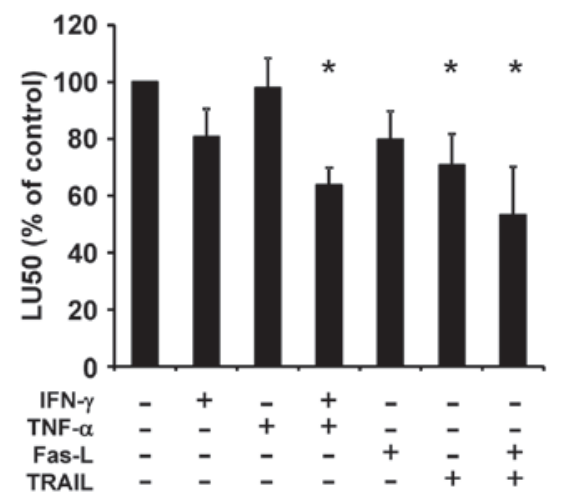

Figure 3. Characterization of aSGMKC cytotoxic activity. (A) Cytotoxic activity of aSGMKCs tested at different effector:target ratios against HCC cell lines (Huh-7, PLC-PRF5) and non-HCC cell lines (HeLa, SK-Hep1). Data are expressed as mean \pm standard error of 6 independent experiments. (B) Percent of CD107a-positive cells in aSGMKCs and LAK cells after a 4 h-culture in the absence (NS) or presence of Huh-7 or K562 target cells. Data are expressed as mean \pm standard error of 3 independent experiments. (C) Percent of CD107a-positive cells gated in NK, NK-like T and T cell subsets in the experiments reported in B. (D) Cytotoxic activity of aSGMKCs incubated with Huh-7 cells in the absence or presence of blocking monoclonal antibodies against IFN- $\gamma$, TNF- $\alpha$, Fas- $L$ or TRAIL. Data are expressed as normalized LU50 (mean \pm standard error) of 7 independent experiments. Control group : $100 \%=587 \pm 286$ LU50 ("P $<0.05$ vs. control). aSGMKCs, allogeneic suicide gene-modified killer cells; HCC, hepatocellular carcinoma; LAK, lymphokine-activated killer; NK, natural killer; IFN- $\gamma$, interferon- $\gamma$; TNF- $\alpha$, anti-tumor necrosis factor- $\alpha$; Fas-L, fas ligand; TRAIL, TNF-related apoptosis inducing ligand; LU50, lytic units $50 \%$.

A

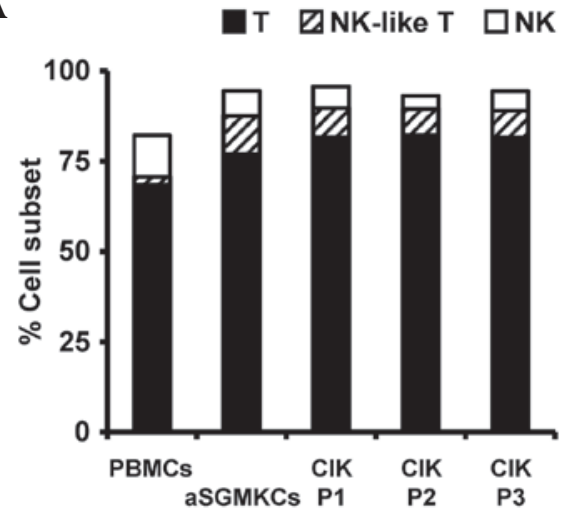

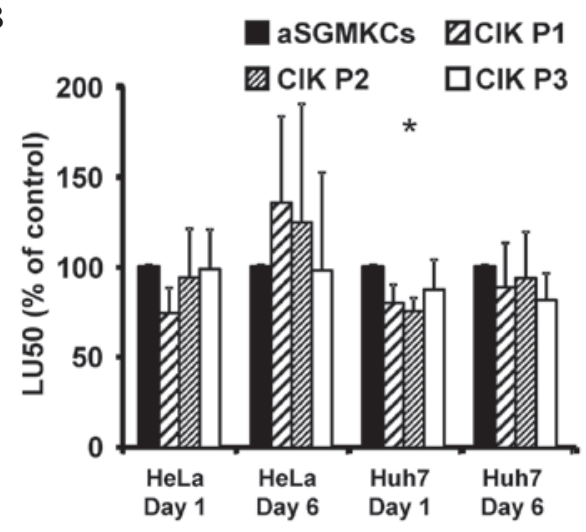

Figure 4. Comparison of aSGMKCs and CIK cells produced according to three different protocols (P1-P3). (A) Frequency of NK (white bars), NK-like T and T cells in aSGMKCs, CIK cells and PBMCs. In a single experiment, aSGMKCs, CIK cells and PBMCs were isolated and produced from the same healthy donor. Data are expressed as the mean of four independent experiments. (B) Cytotoxic activity of aSGMKCs and CIK cells evaluated after day 1 or 6 of co-culture with HeLa and Huh-7 target cells. Data are expressed as normalized LU50 (mean \pm standard error) of five independent experiments. Control groups (aSGMKCs): 100\%=258 \pm 137 LU50 (HeLa, day 1), 752 \pm 362 LU50 (HeLa, day 6), 90 \pm 28 LU50 (Huh-7, day 1) and 162 \pm 53 LU50 (Huh-7, day 6) ("P<0.05 vs. aSGMKCs). aSGMKCs, allogeneic suicide gene-modified killer cells; CIK, cytokine-induced killer; P1/2/3, protocol 1/2/3; NK, natural killer; PBMCs, peripheral blood mononuclear cells; LU50, lytic units 50\%.

Allogeneic SGMKCs are phenotypically and functionally similar to CIK cells. It was previously reported, that aSGMKCs exhibited reduced in vitro and in vivo alloreactivity $(20,34,35)$, in terms of proliferative response and potential of GvHD induction and that their cytotoxicity was non-MHC class I-restricted and predominantly 
Table I. Effect of varied treatments on tumor growth.

Relative tumor growth [median (min-max) $]^{\mathrm{a}}$

\begin{tabular}{|c|c|c|c|c|c|c|}
\hline \multirow[b]{2}{*}{ Treatment } & & \multirow{2}{*}{$\begin{array}{l}\text { Regressing } \\
\text { tumors\% }\end{array}$} \\
\hline & Day 0 & Day 4 & Day 7 & Day 11 & Day 14 & \\
\hline $\begin{array}{l}\text { PBS } \\
(n=13)\end{array}$ & $1.0(1.0-1.0)$ & $2.2(0.1-290.6)$ & $5.9(0.1-440.5)$ & $27.8(0.1-1231.0)$ & $33.3(0.0-1739.3)$ & 23.1 \\
\hline $\begin{array}{l}\text { CIK P1 } \\
(n=14)\end{array}$ & $1.0(1.0-1.0)$ & $0.1^{\mathrm{c}}(0.0-22.9)$ & $0.3^{\mathrm{c}}(0.0-21.5)$ & $0.2^{\mathrm{c}}(0.0-46.2)$ & $0.3^{c}(0.0-104.6)$ & $71.4^{\mathrm{d}}$ \\
\hline $\begin{array}{l}\text { CIK P2 } \\
(n=17)\end{array}$ & $1.0(1.0-1.0)$ & $0.1^{\mathrm{c}}(0.0-22.5)$ & $0.1^{\mathrm{c}}(0.0-193.2)$ & $0.1^{\mathrm{c}}(0.0-297.6)$ & $0.1^{\mathrm{c}}(0.0-137.2)$ & $88.2^{\mathrm{d}}$ \\
\hline $\begin{array}{l}\text { CIK P3 } \\
(n=13)\end{array}$ & $1.0(1.0-1.0)$ & $0.1^{\mathrm{c}}(0.0-1.0)$ & $0.1^{\mathrm{c}}(0.0-1.4)$ & $0.1^{\mathrm{c}}(0.0-26.4)$ & $0.1^{\mathrm{c}}(0.0-26.0)$ & $61.5^{\mathrm{d}}$ \\
\hline $\begin{array}{l}\text { SGMKC } \\
(\mathrm{n}=17)\end{array}$ & $1.0(1.0-1.0)$ & $0.1^{\mathrm{c}}(0.0-16.0)$ & $0.1^{\mathrm{c}}(0.0-41.8)$ & $0.1^{\mathrm{c}}(0.0-109.9)$ & $0.1^{\mathrm{c}}(0.0-110.4)$ & $76.5^{\mathrm{d}}$ \\
\hline $\begin{array}{l}\text { SGMKC + CID } \\
(\mathrm{n}=12)\end{array}$ & $1.0(1.0-1.0)$ & $0.8(0.1-114.7)$ & $1.4(0.0-97.2)$ & $0.3(0.0-136.2)$ & $0.7(0.0-330.7)$ & 25.0 \\
\hline
\end{tabular}

${ }^{a}$ Relative tumor growth represents the ratio of the luciferase activity at the indicated days to the initial luciferase activity at day 0 . A relative tumor growth value of $<1$ (dashed line) indicates tumor cell elimination by effector cells, while a value of $>1$ indicates an expansion of tumor cells. Results are pooled data of three independent experiments. ${ }^{b}$ Frequency of mice with tumor regression, i.e. (number of mice with a relative tumor growth value of $<1 /$ total number of mice) $x 100$, at day $14 .{ }^{c} \mathrm{P}<0.05$ vs. PBS (Mann-Whitney $\mathrm{U}$ test). ${ }^{\mathrm{d}} \mathrm{P}<0.05$ vs. PBS $\left(\chi^{2}\right.$ test, comparing the number of mice with relative tumor growth of $<1 \mathrm{vs}$. the number of mice with relative tumor growth $>1$ ). PBS, phosphate-buffered saline; CIK, cytokine-induced killer; P1/2/3, protocol 1/2/3; SGMKC, suicide gene-modified killer cells; CID, chemical inducer of death.

mediated by NK and NK-like T cells (20). Together with the present observations indicating the involvement of TRAIL in the killing mechanism, this prompted the evaluation of similarities between aSGMKCs and CIK cells, another immunotherapy product identified to provide potent non-MHC class I-restricted anti-tumor activity toward hematologic and solid tumors. Indeed, CIK cells have also previously exhibited NK and NK-like T cell-mediated cytotoxicity and low potential of GvHD induction (39). Thus, the phenotypic and cytotoxic activity of aSGMKCs and CIK cells were compared, generated in parallel from the same healthy donors using three different cell expansion protocols for CIK cell production. There were no significant differences between aSGMKCs and CIK cells in terms of repartition of T, NK-like $\mathrm{T}$ and NK cell subsets (Fig. 4A). Furthermore, the cytotoxic activity of aSGMKCs, evaluated against Huh-7 cells (or HeLa cells, used as a positive control of target cell killing) was similar, or even greater than that of CIK cells, when evaluated following 1 or 6 days of E:T cell co-culture (Fig. 4B).

In vivo anti-tumor effect of aSGMKCs toward hepatoma cells. The data presented was generated using aSGMKCs transduced with an HSV-tk-expressing retroviral vector. However, a new generation of suicide genes, based on the inducible activation of caspase domains, has been recently developed, including the iCasp9 gene (40), whose efficacy has been demonstrated in clinical trials $(26,27)$. This transgene induces rapid killing of aSGMKCs in the presence of their prodrug, CID, as $>95 \%$ of cells are killed within $2 \mathrm{~h}$, as determined by flow cytometry following Annexin V/propidium iodide staining (unpublished data). This is more rapid than the killing of HSV-tk-expressing aSGMKCs by its prodrug, ganciclovir (20,41). Therefore, iCasp9-expressing aSGMKCs were compared with CIK cells using an in vivo cytotoxicity assay. Immunodeficient SCID-bg mice were subcutaneously injected with Huh-7-Luc target cells, in the absence or presence of aSGMKCs or CIK cells, and monitored for tumor growth by BLI. Fig. 5 represents the data obtained for one representative mouse of each group.

When Huh-7-Luc cells were injected alone, the median relative tumor growth was $>1$ at all time points, indicating the expansion of tumor cells (Table I). When CIK cells were co-injected with target cells, the median relative tumor growth values were $<1 \quad(\mathrm{P}<0.05$, Mann-Whitney $\mathrm{U}$ test $)$, indicating that CIK cells exhibited a significant antitumor effect. When aSGMKCs were co-injected with target cells, a similar antitumor effect was also observed $(\mathrm{P}<0.05$, Mann-Whitney $\mathrm{U}$ test). Notably, the antitumor effect of aSGMKCs was reversed by CID administration, confirming that the effect was aSGMKC-mediated (Table I). However, tumor escape occurred in certain (12-38\%) mice injected with aSGMKCs or CIK cells. Therefore, the frequency of mice with tumor regression (a relative tumor growth value $<1$ ) was also evaluated. As indicated by Table I, this frequency was $23.1 \%$ in the control group injected with Huh-7-Luc cells alone, indicating a lack of engraftment in these mice. However, this frequency significantly $\left(\mathrm{P}<0.05, \chi^{2}\right.$ test) increased to $61.5-88.2 \%$ of mice injected with aSGMKCs or CIK cells, indicating tumor rejection in these groups. It is of note that the frequency reversed to $25.0 \%$ in mice receiving aSGMKCs when the prodrug CID was administered at the same time (Table I), indicating that aSGMKCs were rapidly killed, before having time to exert their anti-tumor effects. 


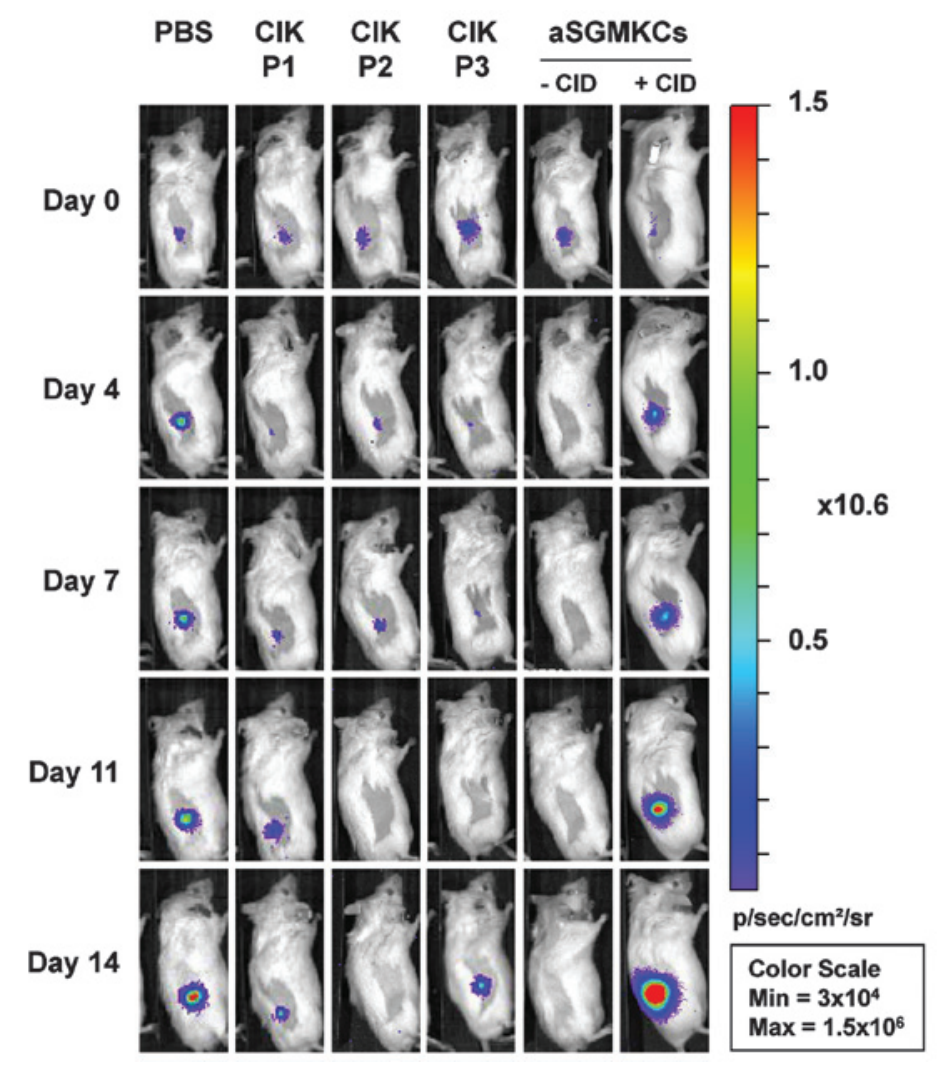

Figure 5. In vivo cytotoxicity assay of CIK cells and aSGMKCs against Huh-7 cells. Mice representative of the experiments reported in Table I were subcutaneously injected with luciferase-expressing Huh-7 cells, in the absence or presence of CIK cells or aSGMKCs, with or without CID and were evaluated for luciferase activity at the indicated days 0-14. For each experimental condition, the same mouse is presented from days 0-14, with the same color scale for all mice and all time points. CIK, cytokine-induced killer; aSGMKCs, allogeneic suicide gene-modified killer cells; CID, chemical inducer of death; PBS, phosphate-buffered saline; P1/2/3, protocol 1/2/3.

\section{Discussion}

A previous study demonstrated (20) that aSGMKCs produced following CD3 plus IL-2 activation, a combination previously described (31) and used in our clinical trial of aSGMKC infusion at time of bone marrow transplantation (24), exhibit a potent non-MHC class I-restricted cytotoxic activity towards $\mathrm{HCC}$ cell lines that is mediated primarily by NK and NK-like $\mathrm{T}$ cells. Numerous studies have indicated that ex vivo-activated autologous PBMCs, previously expanded in similar conditions as the current aSGMKCs [namely CIK cells $(3,5)$ ], however without gene transfer, exhibit phenotypic and functional properties similar to those of the current aSGMKCs, including high cytotoxic activity (6), particularly against HCC cell lines $(4,5)$, and low potential for GvHD induction $(7,8)$. The cytotoxic activity of CIK cells is non-MHC-restricted and is primarily mediated by NK-like T cells (3). To the best of our knowledge, the current study is the first to indicate that, by comparing cells expanded according to protocols used for aSGMKC and CIK cell production, aSGMKCs are suicide-gene-modified CIK cells. The repartition of NK, NK-like T and T cells within aSGMKCs is similar to that observed in CIK cells, and the in vitro and in vivo cytotoxic activity of aSGMKCs is as potent as that obtained with CIK cells. Although further experiments are required, the results of the present study suggest that the association between IFN- $\gamma$, TNF- $\alpha$ and TRAIL, possibly in synergy with Fas-L, all previously demonstrated to be involved in CIK-mediated cell killing, may be involved as an effector mechanism of aSGMKC-induced target cell killing (42-44). Overall, the current results support the hypothesis that aSGMKCs, proposed to be used clinically in an allogeneic setting, are similar to CIK cells, which are currently used clinically in an autologous setting.

Various clinical studies (11-18), several of which were randomized (15-18), comparing TACE, RFA and/or surgery with or without CIK therapy, have demonstrated the ability of this autologous adoptive immunotherapy to reduce HCC recurrence and to increase median time to relapse, relapse-free survival, and overall survival in patients with HCC. These clinical results strengthen the hypothesis that aSGMKCs may exert an anti-tumor effect against HCC, particularly as they are allogeneic; the MHC-restricted and/or non-MHC-restricted alloreactivity of aSGMKCs may provide an additional mechanism for tumor recognition.

Another issue to consider for aSGMKC-based adoptive allogeneic immunotherapy is alloimmunization. As the patients are immunocompetent, an anti-aSGMKC immune response leading to aSGMKC rejection should occur. This is an additional safety element that would limit the risk of long-term aSGMKC toxicity, but it may also limit short-term anti-tumor efficacy. This means that aSGMKCs must be sufficiently cytotoxic to operate quickly and destroy tumor cells prior to being rejected by the patient's immune system. The observations of the current study indicate that high cytotoxic activity in aSGMKCs may be detected within 1 day in vitro and 4 days in vivo (prior to the development of an immune 
response leading to their rejection). In phase I/II clinical trials of infusion of partially HLA-matched EBV-specific allogeneic $\mathrm{T}$ cells for the treatment of post-transplant EBV-induced lymphoma, performed by Haque et al $(45,46)$ infused cells may be detected for up to 44 days following infusion (45), with patients experiencing withdrawal or reduction of immunosuppression for the previous 2-6 weeks. However, in vivo survival was typically limited to $\sim 1$ week. In the phase II study reported by Haque et al (46) complete responses were observed in 14 out of 33 patients despite alloimmunization, indicating that alloimmunization may not represent a strong limitation to adoptive allogeneic immunotherapy if short-term anti-tumor effects are selected. Similarly, Slavin et al (47) performed a phase I trial investigating the infusion of 'intentionally HLA-mismatched IL-2 activated killer' (IMAK) cells produced from normal donors to patients with solid tumors. Rejection of infused IMAK cells was expected to occur within 1 week and was considered a safety mechanism to avoid GvHD. Infusion of IMAK cells was determined to be safe and, among the 35 patients with metastatic solid tumors, only one grade I GvHD was observed.

Taking advantage of the resistance of aSGMKCs to calcineurin inhibitors, such as ciclosporin A and FK506 $(20,48,49)$, it was previously reported in a surrogate mouse model of aSGMKCs that alloimmunization of such effector cells may be prevented in immunocompetent mice, leading to an anti-tumor effect toward a syngeneic HCC cell line (20). However, other methods for preventing alloimmunization should be considered by eliminating or inhibiting regulatory $\mathrm{T}$ cells, using cyclophosphamide or fludarabine-based lymphodepletion protocols $(50,51)$ [as performed by Slavin et al $(47)$ at the time of IMAK infusion] or mTOR inhibitors such as rapamycin [known to also exhibit anti-tumor activity $(52,53)]$. Induction of aSGMKC-specific tolerance by co-infusion of non-depleting CD3 or CD4 monoclonal antibodies $(54,55)$ or by administration of CTLA4-Ig (56) may also be considered.

In conclusion, the present study has demonstrated that aSGMKCs are CIK cells with a high cytotoxic activity towards solid tumors. Therefore, the production of a bank of 'ready-to-use' aSGMKCs for the treatment of solid tumors, particularly for indications of hepatic localization, should be considered. Additionally, their advantages include rapid availability and low potential for GvHD induction, as well as the fact that no clinical batch in the bank may be lost due to last-minute contra-indication from the recipient. To prevent secondary effects leading to toxicity, the suicide gene will allow the specific elimination of aSGMKCs through the administration of the prodrug. The primary issue remaining to be determined is the clinical efficacy of aSGMKCs in immunocompetent animal HCC models, provided that alloimmunization may be controlled by an immunosuppressive and/or lympho-ablative conditioning regimen.

\section{Acknowledgements}

The authors would like to thank Mr. Nicolas Brignon and Mr. Richard Pidl for their excellent animal care. This study was supported by Inserm, the Fondation pour la Recherche Médicale (Comité Alsace), the Ligue Nationale Contre le Cancer (Conférence de Coordination Inter-Régionale
Grand-Est; grant no. 1FI10005LBKD), the Association pour la recherche sur le Cancer (ARC; grant no. SFI20111203529). Dr Eric Robinet was supported by the Agence Nationale pour la Recherche sur le SIDA et les Hépatites Virales (grant no 2008059 ULP). Dr Tao Wu was a recipient of a fellowship of the Alsace Region and Dr Céline Leboeuf was a recipient of fellowships of the Fondation Transplantation and the ARC (grant no. DOC20110603384).

\section{References}

1. El-Serag HB: Epidemiology of viral hepatitis and hepatocellular carcinoma. Gastroenterology 142: 1264-1273.e1, 2012.

2. Llovet JM, Ricci S, Mazzaferro V, Hilgard P, Gane E, Blanc JF, de Oliveira AC, Santoro A, Raoul JL, Forner A, et al; SHARP Investigators Study Group: Sorafenib in advanced hepatocellular carcinoma. N Engl J Med 359: 378-390, 2008.

3. Schmidt-Wolf IG, Lefterova P, Mehta BA, Fernandez LP, Huhn D, Blume KG, Weissman IL and Negrin RS: Phenotypic characterization and identification of effector cells involved in tumor cell recognition of cytokine-induced killer cells. Exp Hematol 21: 1673-1679, 1993.

4. Wang FS, Liu MX, Zhang B, Shi M, Lei ZY, Sun WB, Du QY and Chen JM: Antitumor activities of human autologous cytokine-induced killer (CIK) cells against hepatocellular carcinoma cells in vitro and in vivo. World $\mathrm{J}$ Gastroenterol 8: 464-468, 2002

5. Kim HM, Lim J, Yoon YD, Ahn JM, Kang JS, Lee K, Park SK, Jeong YJ, Kim JM, Han G, et al: Anti-tumor activity of ex vivo expanded cytokine-induced killer cells against human hepatocellular carcinoma. Int Immunopharmacol 7: 1793-1801, 2007.

6. Lu PH and Negrin RS: A novel population of expanded human $\mathrm{CD}^{+} \mathrm{CD}^{2} 6^{+}$cells derived from $\mathrm{T}$ cells with potent in vivo antitumor activity in mice with severe combined immunodeficiency. J Immunol 153: 1687-1696, 1994.

7. Nishimura R, Baker J, Beilhack A, Zeiser R, Olson JA, Sega EI, Karimi $M$ and Negrin RS: In vivo trafficking and survival of cytokine-induced killer cells resulting in minimal GVHD with retention of antitumor activity. Blood 112: 2563-2574, 2008.

8. Baker J, Verneris MR, Ito M, Shizuru JA and Negrin RS: Expansion of cytolytic CD8(+) natural killer T cells with limited capacity for graft-versus-host disease induction due to interferon gamma production. Blood 97: 2923-2931, 2001

9. Olioso P, Giancola R, Di Riti M, Contento A, Accorsi P and Iacone A: Immunotherapy with cytokine induced killer cells in solid and hematopoietic tumours: A pilot clinical trial. Hematol Oncol 27: 130-139, 2009.

10. Shi M, Zhang B, Tang ZR, Lei ZY, Wang HF, Feng YY, Fan ZP, $\mathrm{Xu}$ DP and Wang FS: Autologous cytokine-induced killer cell therapy in clinical trial phase I is safe in patients with primary hepatocellular carcinoma. World J Gastroenterol 10: 1146-1151, 2004.

11. Hao MZ, Lin HL, Chen Q, Ye YB, Chen QZ and Chen MS: Efficacy of transcatheter arterial chemoembolization combined with cytokine-induced killer cell therapy on hepatocellular carcinoma: a comparative study. Chin J Cancer 29: 172-177, 2010.

12. Huang ZM, Li W, Li S, Gao F, Zhou QM, Wu FM, He N, Pan CC, Xia JC, Wu PH and Zhao M: Cytokine-induced killer cells in combination with transcatheter arterial chemoembolization and radiofrequency ablation for hepatocellular carcinoma patients. J Immunother 36: 287-293, 2013.

13. Pan K, Li YQ, Wang W, Xu L, Zhang YJ, Zheng HX, Zhao JJ, Qiu HJ, Weng DS, Li JJ, et al: The efficacy of cytokine-induced killer cell infusion as an adjuvant therapy for postoperative hepatocellular carcinoma patients. Ann Surg Oncol 20: 4305-4311, 2013.

14. Cui J, Wang N, Zhao H, Jin H, Wang G, Niu C, Terunuma H, $\mathrm{He} \mathrm{H}$ and $\mathrm{Li}$ W: Combination of radiofrequency ablation and sequential cellular immunotherapy improves progression-free survival for patients with hepatocellular carcinoma. Int J Cancer 134: 342-351, 2014.

15. Weng DS, Zhou J, Zhou QM, Zhao M, Wang QJ, Huang LX, Li YQ, Chen SP, Wu PH and Xia JC: Minimally invasive treatment combined with cytokine-induced killer cells therapy lower the short-term recurrence rates of hepatocellular carcinomas. J Immunother 31: 63-71, 2008. 
16. Yu X, Zhao H, Liu L, Cao S, Ren B, Zhang N, An X, Yu J, $\mathrm{Li} \mathrm{H}$ and Ren X: A randomized phase II study of autologous cytokine-induced killer cells in treatment of hepatocellular carcinoma. J Clin Immunol 34: 194-203, 2014.

17. Lee JH, Lee JH, Lim YS, Yeon JE, Song TJ, Yu SJ, Gwak GY, Kim KM, Lee JW and Yoon JH: Adjuvant immunotherapy with autologous cytokine-induced killer cells for hepatocellular carcinoma. Gastroenterology 148: 1383-1391.e6, 2015.

18. Takayama T, Sekine T, Makuuchi M, Yamasaki S, Kosuge T, Yamamoto J, Shimada K, Sakamoto M, Hirohashi S, Ohashi Y and Kakioze T: Adoptive immunotherapy to lower postsurgical recurrence rates of hepatocellular carcinoma: A randomised trial. Lancet 356: 802-807, 2000.

19. Li X, Dai D, Song X, Liu J, Zhu L and Xu W: A meta-analysis of cytokine-induced killer cells therapy in combination with minimally invasive treatment for hepatocellular carcinoma. Clin Res Hepatol Gastroenterol 38: 583-591, 2014.

20. Leboeuf C, Mailly L, Wu T, Bour G, Durand S, Brignon N, Ferrand $\mathrm{C}$, Borg $\mathrm{C}$, Tiberghien $\mathrm{P}$, Thimme $\mathrm{R}$ et al: In vivo proof of concept of adoptive immunotherapy for hepatocellular carcinoma using allogeneic suicide gene-modified killer cells. Mol Ther 22: 634-644, 2014.

21. Ciceri F, Bonini C, Marktel S, Zappone E, Servida P, Bernardi M, Pescarollo A, Bondanza A, Peccatori J, Rossini S, et al: Antitumor effects of HSV-TK-engineered donor lymphocytes after allogeneic stem-cell transplantation. Blood 109: 4698-4707, 2007.

22. Deschamps M, Mercier-Lethondal P, Certoux JM, Henry C, Lioure B, Pagneux C, Cahn JY, Deconinck E, Robinet E, Tiberghien $\mathrm{P}$ and Ferrand C: Deletions within the HSV-tk transgene in long-lasting circulating gene-modified $\mathrm{T}$ cells infused with a hematopoietic graft. Blood 110: 3842-3852, 2007

23. Zhou X, Di Stasi A, Tey SK, Krance RA, Martinez C, Leung KS Durett AG, Wu MF, Liu H, Leen AM, et al: Long-term outcome after haploidentical stem cell transplant and infusion of T cells expressing the inducible caspase 9 safety transgene. Blood 123 : 3895-3905, 2014.

24. Tiberghien P, Ferrand C, Lioure B, Milpied N, Angonin R, Deconinck E, Certoux JM, Robinet E, Saas P, Petracca B, et al: Administration of herpes simplex-thymidine kinase-expressing donor T cells with a T-cell-depleted allogeneic marrow graft. Blood 97: 63-72, 2001.

25. Bonini C, Ferrari G, Verzeletti S, Servida P, Zappone E, Ruggieri L, Ponzoni M, Rossini S, Mavilio F, Traversari C and Bordignon C: HSV-TK gene transfer into donor lymphocytes for control of allogeneic graft-versus-leukemia. Science 276 $1719-1724,1997$.

26. Di Stasi A, Tey SK, Dotti G, Fujita Y, Kennedy-Nasser A, Martinez C, Straathof K, Liu E, Durett AG, Grilley B, et al: Inducible apoptosis as a safety switch for adoptive cell therapy. $\mathrm{N}$ Engl J Med 365: 1673-1683, 2011.

27. Zhou X, Dotti G, Krance RA, Martinez CA, Naik S, Kamble RT, Durett AG, Dakhova O, Savoldo B, Di Stasi A, et al: Inducible caspase-9 suicide gene controls adverse effects from alloreplete $\mathrm{T}$ cells after haploidentical stem cell transplantation. Blood 125: 4103-4113, 2015.

28. Ott PA, Herzog BA, Quast S, Hofstetter HH, Boehm BO, Tary-Lehmann M, Durinovic-Bello I, Berner BR and Lehmann PV: Islet-cell antigen-reactive T cells show different expansion rates and Th1/Th2 differentiation in type 1 diabetic patients and healthy controls. Clin Immunol 115: 102-114, 2005.

29. Imataki O, Heike $Y$, Makiyama H, Iizuka A, Ikarashi $Y$, Ishida $T$, Wakasugi $\mathrm{H}$ and Takaue $\mathrm{Y}$ : Insufficient ex vivo expansion of Valpha24(+) natural killer $\mathrm{T}$ cells in malignant lymphoma patients related to the suppressed expression of CD1d molecules on CD14(+) cells. Cytotherapy 10: 497-506, 2008.

30. Vickers MA, Wilkie GM, Robinson N, Rivera N, Haque T, Crawford DH, Barry J, Fraser N, Turner DM, Robertson V, et al: Establishment and operation of a good manufacturing practice-compliant allogeneic Epstein-Barr virus (EBV)-specific cytotoxic cell bank for the treatment of EBV-associated lymphoproliferative disease. Br J Haematol 167: 402-410, 2014.

31. Robinet E, Certoux JM, Ferrand C, Maples P, Hardwick A, Cahn JY, Reynolds CW, Jacob W, Hervé P and Tiberghien P: A closed culture system for the ex vivo transduction and expansion of human T lymphocytes. J Hematother 7: 205-215, 1998.

32. Tey SK, Dotti G, Rooney CM, Heslop HE and Brenner MK: Inducible caspase 9 suicide gene to improve the safety of allodepleted $\mathrm{T}$ cells after haploidentical stem cell transplantation. Biol Blood Marrow Transplant 13: 913-924, 2007.
33. Kühlcke K, Ayuk FA, Li Z, Lindemann C, Schilz A, Schade UM, Fauser AA, Zander AR, Eckert HG and Fehse B: Retroviral transduction of $\mathrm{T}$ lymphocytes for suicide gene therapy in allogeneic stem cell transplantation. Bone Marrow Transplant 25 (Suppl 2): S96-S98, 2000

34. Mercier-Letondal P, Montcuquet N, Sauce D, Certoux JM, Jeanningros S, Ferrand C, Bonyhadi $M$, Tiberghien $\mathrm{P}$ and Robinet E: Alloreactivity of ex vivo-expanded T cells is correlated with expansion and CD4/CD8 ratio. Cytotherapy 10: 275-288, 2008.

35. Sauce D, Tonnelier N, Duperrier A, Petracca B de Carvalho Bittencourt M, Saadi M, Saas P, Ferrand C, Herve P, Tiberghien $P$ and Robinet E: Influence of ex vivo expansion and retrovirus-mediated gene transfer on primary $\mathrm{T}$ lymphocyte phenotype and functions. J Hematother Stem Cell Res 11: 929-940, 2002.

36. Fehse B, Kustikova OS, Li Z, Li Z, Wahlers A, Bohn W, Beyer WR, Chalmers D, Tiberghien P, Kühlcke K, Zander AR and Baum C: A novel 'sort-suicide' fusion gene vector for T cell manipulation. Gene Ther 9: 1633-1638, 2002.

37. Chan JK, Hamilton CA, Cheung MK, Karimi M, Baker J, Gall JM, Schulz S, Thorne SH, Teng NN, Contag CH et al: Enhanced killing of primary ovarian cancer by retargeting autologous cytokine-induced killer cells with bispecific antibodies: A preclinical study. Clin Cancer Res 12: 1859-1867, 2006

38. Shi Y, Wu W, Wan T, Liu Y, Peng G, Chen Z and Zhu H: Impact of polyclonal anti-CD3/CD28-coated magnetic bead expansion methods on $\mathrm{T}$ cell proliferation, differentiation and function. Int Immunopharmacol 15: 129-137, 2013.

39. Rutella S and Locatelli F: Is there a role for cytokine-induced killer cells in cancer immunotherapy? Immunotherapy 4: 867-869, 2012.

40. Straathof KC, ulè MA, Yotnda P, Dotti G, Vanin EF, Brenner MK, Heslop HE, Spencer DM and Rooney CM: An inducible caspase 9 safety switch for T-cell therapy. Blood 105: 4247-4254, 2005.

41. Marin V, Cribioli E, Philip B, Tettamanti S, Pizzitola I, Biondi A, Biagi E and Pule M: Comparison of different suicide-gene strategies for the safety improvement of genetically manipulated T cells. Hum Gene Ther Methods 23: 376-386, 2012

42. Rajbhandary S, Zhao MF, Zhao N, Lu WY, Zhu HB, Xiao X, Deng Q and Li YM: Multiple cytotoxic factors involved in IL-21 enhanced antitumor function of CIK cells signaled through STAT-3 and STAT5b pathways. Asian Pac J Cancer Prev 14: 5825-5831, 2013.

43. Hu L, Cao D, Li Y, He Y and Guo K: Resveratrol sensitized leukemia stem cell-like KG-1a cells to cytokine-induced killer cells-mediated cytolysis through NKG2D ligands and TRAIL receptors. Cancer Biol Ther 13: 516-526, 2012.

44. Franceschetti M, Pievani A, Borleri G, Vago L, Fleischhauer K, Golay $\mathrm{J}$ and Introna M: Cytokine-induced killer cells are terminally differentiated activated CD8 cytotoxic T-EMRA lymphocytes. Exp Hematol 37: 616-628, 2009.

45. Haque T, Wilkie GM, Taylor C, Amlot PL, Murad P, Iley A, Dombagoda D, Britton KM, Swerdlow AJ and Crawford DH: Treatment of Epstein-Barr-virus-positive post-transplantation lymphoproliferative disease with partly HLA-matched allogeneic cytotoxic T cells. Lancet 360: 436-442, 2002.

46. Haque T, Wilkie GM, Jones MM, Higgins CD, Urquhart G, Wingate P, Burns D, McAulay K, Turner M, Bellamy C, et al: Allogeneic cytotoxic T-cell therapy for EBV-positive posttransplantation lymphoproliferative disease: results of a phase 2 multicenter clinical trial. Blood 110: 1123-1131, 2007.

47. Slavin S, Ackerstein A, Or R, Shapira MY, Gesundheit B, Askenasy $\mathrm{N}$ and Morecki S: Immunotherapy in high-risk chemotherapy-resistant patients with metastatic solid tumors and hematological malignancies using intentionally mismatched donor lymphocytes activated with rIL-2: A phase I study. Cancer Immunol Immunother 59: 1511-1519, 2010.

48. Contassot E, Robinet E, Angonin R, Laithier V, Bittencourt M, Pavy JJ, Cahn JY, Hervé P and Tiberghien P: Differential effects of cyclosporin A on the alloreactivity of fresh and ex vivo-expanded T lymphocytes. Bone Marrow Transplant 22: 1097-1102, 1998.

49. Maury S, Litvinova E, Boyer O, Benard L, Bruel S, Klatzmann D and Cohen JL: Effect of combined cytostatic cyclosporin A and cytolytic suicide gene therapy on the prevention of experimental graft-versus-host disease. Gene Ther 9: 201-207, 2002.

50. Dudley ME, Wunderlich JR, Yang JC, Sherry RM, Topalian SL, Restifo NP, Royal RE, Kammula U, White DE, Mavroukakis SA et al: Adoptive cell transfer therapy following non-myeloablative but lymphodepleting chemotherapy for the treatment of patients with refractory metastatic melanoma. J Clin Oncol 23: 2346-2357, 2005. 
51. Ghiringhelli F, Menard C, Puig PE, Ladoire S, Roux S, Martin F, Solary E, Le Cesne A, Zitvogel L and Chauffert B: Metronomic cyclophosphamide regimen selectively depletes $\mathrm{CD} 4^{+} \mathrm{CD} 25^{+}$regulatory $\mathrm{T}$ cells and restores $\mathrm{T}$ and $\mathrm{NK}$ effector functions in end stage cancer patients. Cancer Immunol Immunother 56: 641-648, 2007.

52. Zhang JF, Liu JJ, Lu MQ, Cai CJ, Yang Y,Li H, Xu C and Chen GH Rapamycin inhibits cell growth by induction of apoptosis on hepatocellular carcinoma cells in vitro. Transpl Immunol 17: $162-168,2007$.

53. Semela D, Piguet AC, Kolev M, Schmitter K, Hlushchuk R, Djonov V, Stoupis C and Dufour JF: Vascular remodeling and antitumoral effects of mTOR inhibition in a rat model of hepatocellular carcinoma. J Hepatol 46: 840-848, 2007.
54. Martin A, Tisch RM and Getts DR: Manipulating T cell-mediated pathology: Targets and functions of monoclonal antibody immunotherapy. Clin Immunol 148: 136-147, 2013.

55. Waldmann H, Adams E and Cobbold S: Reprogramming the immune system: Co-receptor blockade as a paradigm for harnessing tolerance mechanisms. Immunol Rev 223: 361-370, 2008.

56. Fife BT and Bluestone JA: Control of peripheral T-cell tolerance and autoimmunity via the CTLA-4 and PD-1 pathways. Immunol Rev 224: 166-182, 2008 